\section{Edyrcasaia

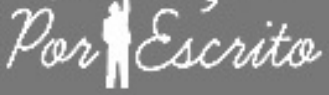

ARTIGO

\section{Editor}

Maria Inês Côrte Vitoria PUCRS, RS, Brasil

\section{Editor Executivo}

Pricila Kohls dos Santos PUCRS, RS, Brasil

\section{Equipe Editorial}

Rosa Maria Rigo PUCRS, RS, Brasil

Carla Spagnolo PUCRS, RS, Brasil Martha Luci Sozo PUCRS, RS, Brasil Dirce Hechler Herbertz PUCRS, RS, Brasil

\section{ISSN 2179-8435}

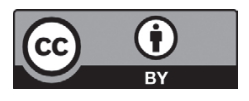

Este artigo está licenciado sob forma de uma licenç Creative Commons Atribuição 4.0 Internacional, que permite uso irrestrito, distribuiçăo e reproduçāo em qualquer meio, desc corretamente citada. http://creativecommons.org/licenses/by/4.0/deed.pt BP

\title{
Sobre educação, antropologia, ética e linguagem, na era tecnológica
}

\author{
About education, antropology, language, on tehcnological times \\ Acerca de la educación, antropología, lenguaje en la era tecnológica
}

\section{Rosa Maria Filippozzi Martinia}

RESUMO: O presente trabalho aborda temas importantes para a educação brasileira tais como antropologia, ética e tecnologia de maneira que seu aprofundamento possa contribuir para discussões e ações que promovam um desenvolvimento sustentável. Para tanto se detém na análise da antropologia como filosofia primeira, na ética da solicitude como aspectos fundamentais para a formação de professores. O trabalho discute as questões das tecnologias de comunicação como condição para um ensino significativo.

Palavras-chave: educação; antropologia; ética; tecnologia; linguagem.

ABSTRACT: This paper develops fundamental issues of Brazilian education as anthropology, Ethics and Thecnology in order to discuss profoundly and contribute to discussions and actions to improve a sustainable development. The work points out anthropology as a first philosophy and the solicitude ethics as main dimentions of teacher formation. The work develops also communication and technological problems to significant learning.

Keywords: education; anthropology; ethics; technology; language.

RESUMEN: El presente artículo aborda domínios importantes para la educación brasileña, tales como antropología, ética y tecnologia, de forma que su profundizar pueda contribuir para discusiones y aciones em favor de un desarrollo sustentable. Para tanto se concentra en el análisis de la antropologia como uma filosofia primera, en la ética de la solicitud en tanto que dimensiones fundamentales para la formación de docentes. El trabajo trata de questiones de tecnología de la comunicación para una enseñanza significativa.

Palabras clave: educación; antropología; ética; tecnología; lenguaje.

a Professora titular aposentada de Filosofia do Departamento de Estudo Básicos da Faculdade de Educação da UFRGS. Professora do Mestrado e Doutorado da UNILASALLE. 


\section{Introdução}

$\mathrm{O}$ documento final da Conferência Brasileira de Educação (CONAE) 2014 apresenta no Eixo III Educação, Trabalho e Desenvolvimento sustentável: cultura, ciência, tecnologia, saúde, meio ambiente, uma ênfase no desenvolvimento econômico e desenvolvimento humano, afirmando que um desenvolvimento sustentável necessita de uma intervenção de políticas de Estado, pois desde a década de 80 do século XX, acentuou-se o neocapitalismo globalizado que estimulou apenas a competição e concentração de renda e esqueceu as políticas sociais de saúde, educação, trabalho, cultura, meio ambiente, não só como cuidado e restauração, mas como saneamento básico que ainda falta em todo o país,especialmente nas populações carentes. Ainda nesse Eixo III, p. 54, item b, afirma-se: compreender trabalho, educação, diversidade cultural, ética e meio ambiente como eixos estruturadores do desenvolvimento sustentável. Por outro lado, na p. 57 do mesmo documento, item 3.3 fica explicitado: Dotar as instituições educativas de tecnologias de informação e comunicação (TIC) de recursos pedagógicos apropriados à aprendizagem, considerando as diferentes linguagens midiáticas, assim como garantir sua utilização para fins pedagógicos.

Ainda no mesmo documento, Eixo IV do relatório da CONAE 2014, que trata da Qualidade da Educação: Democratização do acesso, permanência, avaliação, condições de participação e aprendizagem, podemos ver, na p. 64 a caracterização de educação de qualidade como aquela que contribui com a formação de estudantes nos aspectos humanos, sociais, culturais, filosóficos, científicos, históricos, antropológicos, afetivos, econômicos, ambientais e políticos para o desempenho de seu papel de cidadão no mundo, tornando-se, uma qualidade referenciada ao social.

O presente texto gira em torno da suposição de que todos os aspectos mencionados, retirados do texto do relatório da Conferência Nacional de Educação CONAE 2014, poderiam estar de certa forma contidos em uma Antropologia, como filosofia primeira, segundo Tugendhat (2006, p. 76-94).

Tugendhat (2006) explica o que ele entende por uma Antropologia como filosofia primeira, estando esta bem longe da antropologia do iluminismo, e da antropologia cultural norte-americana, em seu objetivismo, e funcionalismo. Também não é a antropologia do estruturalismo a qual Ricoeur (1990), em Soi même comme um autre, criticou como um excesso de formalismo.

Tanto Tugendhat como Ricoeur se preocupam com uma antropologia que tem a ver com a pergunta pela compreensão dos seres humanos, tanto deles mesmos, como do mundo e do outro. Seguindo a hipótese de Tugendhat e de Ricoeur podemos voltar aos gregos, a Platão e Aristóteles, pois trata-se não só de uma pergunta que fazemos a nós mesmos, mas um questionamento de mim mesmo e do outro que me interpela, de um nós intersubjetivo, quando nos perguntamos uns aos outros e a nós mesmos: o que é isso ser humano? 
Essa sugestão de Tugendhat e que, certamente podemos encontrar de forma implícita em Ricoeur, podem ser justificadas a partir dos gregos porque foram eles, que tendo rompido com o pensamento mítico, descobriram um tipo de saber ao qual, desde então, pode se chamar de Filosofia. Tugendhat e Ricoeur de certa forma estão de acordo que não seria a Metafísica a filosofia primeira, mas sim a Antropologia, pois é ela que, em seu movimento reflexivo, pergunta sobre que espécie de ser é este, quando empregamos a palavra homem. Além disso, é este ser humano, como homo sapiens que é capaz de se perguntar: que tipo de vida quero viver?

Tugendhat se vale de Kant em sua Lógica (Ak., IX, 25) para destacar as perguntas fundamentais para uma Filosofia. São elas: $O$ que posso conhecer? (epistemologia); $O$ que devo fazer? (ética) e $O$ que me é permitido esperar? (religião). Estas três perguntas, segundo Kant, poderiam estar resumidas na pergunta $O$ que é o homem? Tugendhat chama atenção no sentido de que com essas perguntas Kant não estaria falando apenas como um iluminista, ou como alguém que fala de diferentes tradições culturais, mas sim da pergunta: O que somos nós, enquanto seres humanos?, e é neste "nós" que se revela o aspecto reflexivo da Antropologia.

Segundo Tugendhat, Kant deveria ter usado a primeira pessoa do plural também para o que podemos entender quando pronunciamos a palavra homem, porque a pergunta antropológica não serve apenas para designar uma espécie, mas significa que temos um entendimento compartilhado do significado de anthropos o qual nos leva a entender que somos seres que podemos dialogar uns com os outros, na medida em que temos a capacidade de falar.

Leonardo Boff (2009) parece também concordar com Tugendhat e Ricoeur quando afirma que só no século $\mathrm{XX}$ as duas guerras mundiais e outras guerras locais que a elas deram seguimento provocaram a morte de duzentos milhões de pessoas e faz a pergunta: Como não se questionar sobre a natureza deste ser complexo, contraditório, anjo bom e satã da terra que é o ser humano?

Santaella (2010) qualifica a contemporaneidade como uma era pós-humana, na qual ocorre um agudo antagonismo entre os polos da psique humana, na medida em que a evolução tecnológica tem propiciado um crescimento desmedido da complexidade da relação natureza e cultura e consequentemente da natureza humana.

As ênfases que retiramos do relatório da CONAE 2014 convergem para a questão da educação de qualidade na contemporaneidade, da tecnologia, e de como esse ser humano, fruto dessa era, poderá ser concebido e educado e com quais recursos. Por isso tentamos eleger o tema da antropologia, da ética e da cultura tecnológica como elementos que podem agrupar as questões levantadas a partir do documento da CONAE 2014. Este trabalho vai tratar, portanto, das concepções antropológicas de dois filósofos do século XX e de algumas observações a respeito da cultura tecnológica que complementarão essas posições. Pretendemos contribuir dessa forma para acrescentar algumas reflexões filosóficas aos temas selecionados do documento da CONAE $2014^{1}$.

1 Ver o relatório do documento da Conferência Nacional de Educação CONAE/MEC 2014. 


\section{A posição de Tugendhat}

Tugendhat elucida sua posição, citando o primeiro livro da República da Platão (352a) em que Sócrates, em seu diálogo com Trasímaco diz: Não estamos tratando de uma questão qualquer, mas sim da maneira como se deve viver. A palavra "deve" não tem, nesse texto o sentido de obrigação, mas sim do bem viver humano. Apenas os humanos, em diferença com outras espécies, são capazes de colocar sua própria vida em questão e decidir se a forma que estão vivendo é a melhor e, como não somos de arame rígido, podemos duvidar de nossa forma de viver e de como nos conduzimos em nossas vidas ${ }^{2}$.

Tugendhat (2006) menciona também Aristóteles, no segundo capítulo de sua Política que se propõe a esclarecer a estrutura social dos seres humanos. Essa tem como ponto de comparação, entre homens e animais, a linguagem humana que o Estagirita chama de logos, referindo-se a estrutura predicativa da linguagem humana, que sendo proposicional, difere de outros animais sociais como as abelhas que se comunicam entre elas por seus estados sensitivos. O fenômeno geral que Aristóteles especifica é que, na linguagem proposicional, termos singulares fazem com que o conteúdo do que é dito se torne independente da situação em que se fala. Desta forma, somente os humanos podem falar do bem. Na linguagem humana, o interlocutor em vez de simplesmente reagir responde explícita ou implicitamente com um sim ou um não, ou devolve a pergunta com uma dúvida, portanto a linguagem humana tem uma característica de ser independente não só da situação, mas também da própria comunicação. No animal, os componentes do contexto do real e o desejo estão sempre associados. No ser humano, as características de sua linguagem o levam a pensar e pensar implica em dúvida e deliberação. Sendo assim, podemos deliberar sob a forma de dois tipos de proposições: as assertóricas por meio das quais damos razões para a busca da verdade e as optativas por meio das quais encontramos razões para justificar o que é bom. Tugendhat prossegue pensando a partir de Aristóteles, e isso implica em afirmar que o ser humano sendo um animal de linguagem é também, em função da linguagem, um animal deliberativo e isso pressupõe questionamento, racionalidade, liberdade e responsabilidade. É ainda a partir da Política de Aristóteles, no segundo capítulo, que Tugendhat afirma que justamente por ser um ser de linguagem que o ser humano é um animal político e cultural. A partir dessas constatações, o autor também afirma que a evolução biológica é superada pela linguagem e pela cultura por um novo mecanismo de transmissão muito mais dinâmico do que a transmissão genética, a qual, entretanto, permanece como base (TUGENDHAT, 2006³).

\footnotetext{
${ }^{2-3}$ As citações de Sócrates e Aristóteles são do próprio Tugendhat. Por outro lado, os neurobiólogos como CHANGEUX, Jean Pierre (2001) e os pós-darwinistas como DAWKINS, Richard (1985) e GOULD, Stefen Jay (2005) são unânimes em afirmar que a capacidade de falar foi uma das condições do aparecimento do homo sapiens.
}

Educação Por Escrito, Porto Alegre, v. 7, n. 1, p. 16-33, jan.-jun. 2016 
Tugendhat justifica simultaneamente tanto a Antropologia como filosofia primeira, como a virada linguística da própria Filosofia, na medida em que, como consequência imediata da linguagem proposicional, é alcançado um novo nível cognitivo, tanto no pensamento instrumental, como no social, permitindo também com sua flexibilidade uma nova ordem na adaptação ao meio ambiente que implicou, emcomparação com o genético, um novo mecanismo de transmissão, de acumulação da aprendizagem de uma geração a outra, permitindo a transmissão cultural e histórica. Tugendhat explica o seu ponto de partida por meio da linguagem para caracterizar a Antropologia como filosofia primeira, porque as Antropologias Filosóficas do século XX começavam por qualificar o homem como ser de liberdade e autoconsciência e ele pretende defender a linguagem como ponto de partida central para uma Antropologia, pois essas outras características decorrem da própria linguagem. Tugendhat acrescenta que a consideração da linguagem proposicional, como núcleo principal para entender o que é próprio da espécie ânthropos, tem a vantagem de esclarecer as funções que a aquisição da linguagem teve para a sobrevivência e como a mesma se tornou uma condição para que a espécie humana pudesse surgir no processo da evolução biológica. Outras características ligadas a linguagem, é a consciência de tempo e a originalidade de uma enorme gama das emoções humanas. A música e as artes são outras formas de expressão tipicamente humanas que Tugendhat hesita em ligá-las à linguagem, mas a esse respeito seriainteressante trazer a contribuição de Ricoeur que associa a linguagem à imaginação e esta desenvolve uma atividade mimética capaz de produzir totalidades de sentido que fazem parte das capacidades expressivas do ser humano (Tugendhat, 2006). Ricoeur (1983) recorre a Poética de Aristóteles e fala da mímesis como imitação ou representação de uma ação, mas tal atividade mimética não se reduz a uma simples cópia, envolve expressão e imaginação, envolve um certo tipo de fazer humano (poiésis) que são as artes e a composição. Ricoeur parece, portanto, responder á dúvida de Tugendhat utilizando Aristóteles para demonstrar que o ser humano, além de ser um animal que fala, sendo por isso um ser político, é um animal que se expressa de diversas formas, tais como a música e as artes.

Tugendhat (2006) nos apresenta ainda a relação da Antropologia Filosófica, nos termos em que ele a entende como Filosofia primeira, e a Antropologia Cultural, considerando a possibilidade dessa relação como uma dinâmica hermenêutica que se realiza na primeira e segunda pessoa. A Antropologia cultural ou etnologia estuda as culturas, descrevendo-as e compreendendo-as, mas realiza seu trabalho de forma objetiva, na terceira pessoa. O autor afirma que só vê a possibilidade de relação entre uma Antropologia Filosófica e uma Antropologia Cultural na medida em que as culturas fossem interlocutoras e participantes de um diálogo imaginário, em que as estruturas das outras culturas pudessem ser vistas potencialmente como estruturas da nossa própria cultura. O diálogo seria sempre na primeira e na segunda pessoa, pois o movimento de compreensão da outra cultura se colocaria de forma intersubjetiva, a partir do qual o entendimento da vida em outras culturas pudesse ser visto como uma possibilidade de nossas próprias 
vidas. Tugendhat resume suas reflexões afirmando; A Antropologia Filosófica é essencialmente reflexiva, mas como não tem um caráter a priori, é suscetível de ser corrigida pela etnologia (2006, p. 86-87).

Tugendhat (2006) faz ainda um reparo ao pensamento de Gadamer, no sentido de sua afirmação de que podemos nos inserir na compreensão de qualquer tradição de forma hermenêutica. A ideia de trabalhar na primeira e segunda pessoa implica em utilizarmos um "nós" que estaria realizando um exame crítico tanto de nossa própria cultura ocidental, como das outras culturasdiferentes da nossa.

Voltando á pergunta sobre o bem e o que significa viver uma vida boa, Tugendhat (2006) exclui a possibilidade de um imperativo categórico, como Kant afirmava, visto que apergunta pelo bem não pode emanar de um mandamento. A pergunta pelo bem não pode ter como alvo algo necessário, mas apenas possível para o qual se podem apresentar boas razões.

Tugendhat (2006) afirma que a pergunta pelo bem implica em um núcleo mais sucinto que é o da moral que por sua vez é envolvido por um contexto mais amplo que podemos chamar de ética. Como vivemos contemporaneamente numa sociedade laica, o único núcleo moral que podemos divisar de forma hipotética é o de um contratualismo simétrico, ou seja, o de manter exigências recíprocas, mas cada um pode ter suas próprias razões sobre o que julga viver bem, desde que mantenha no seu horizonte o respeito às exigências recíprocas.

Tugendaht (2006) apresenta então uma mística laica, já que crer em um Deus, implica a suposição de uma existência que não se pode justificar intersubjetivamente. $O$ autor entende essa mística laica como uma atitude humana que não remete a algo histórico, nem ao sobrenatural. Para essa mística laica o autor afirma que basta recolher-se em si mesmo e olhando para a totalidade do mundo tomar consciência de nossa própria insignificância. Este é um sentimento que comparado a outros é uma possibilidade para a qual se tem boas razões. Além disso, é uma atitude duradoura no tempo, pois é possível mantê-la em todas as condições da vida,uma vez que abarca a totalidade da vida. $\mathrm{O}$ autor cuja posição reconstruímos no texto faz ainda uma observação que não se trata da relação à história, entendida como conexão contínua e diacrônica de uma tradição. Trata-se agora simplesmente de uma pluralidade de posições, não de uma continuidade temporal e causal e ainda conclui que uma Antropologia como filosofia primeira se opõe tanto à metafísica, como a qualquer uma das tradições, visto que nenhuma delas pode falar na primeira e segunda pessoa ${ }^{4}$.

Seria oportuno acrescentar uma interrogação de Lilian do Valle (2014) em seu artigo Para além do sujeito isolado, modelos antropológicos para pensar a educação, que questiona porque há resistência na área da educação

4 Tugendhat com essas expressões primeira e segunda pessoas se refere a uma pragmática da linguagem, na qual a primeira e segunda pessoas têm força ilocucionária e a terceira só expressa constatações relativas a fatos.

Educação Por Escrito, Porto Alegre, v. 7, n. 1, p. 16-33, jan.-jun. 2016 
com relação à antropologia que indaga justamente o que é ser humano? Lilian do Valle prossegue em suas observações, afirmando que compreende essa resistência dos professores com relação à Antropologia Filosófica, porque esta se pauta por uma posição metafísica, que assimilou o estudo do humano em condições de busca por determinações universais, supra-humanas e extrassociais. Justamente as críticas de Tugendhat (2006) são contra o fundamento metafísico para a questão do humano e as propostas desse autor são no sentido de usar a linguagem para deliberar, na primeira e segunda pessoa o que é desejável e o que é provável para um ser humano que usa a linguagem para justificar suas escolhas, sejam elas instrumentais cognitivas ou práticas, relativas a sentimentos e desejos do que se considera viver bem, que não podem ser feitas na terceira pessoa, pois tornaria o ser humano objetivável, mas se trata de questionar, intersubjetivamente, entre seres humanos, o que seria o viver bem. Trata-se, pois como afirma Do Valle (2014) de buscar condições de inteligibilidade para dois tipos de ser humano: o professor e o aluno. Esta inteligibilidade e condição também para a interdisciplinaridade, pois sem a abertura para o outro, o diferente não pode haver isso que consideramos interdisciplinaridade. Do Valle, no mesmo artigo critica os excessos de cognitivismo e uma compreensão reducionista da complexidade humana.

Encerrando a revisão de Lilian do Valle (2014) há uma recomendação para que se volte aos antigos. Entende-se com isso uma volta à Platão e Aristóteles. Segundo a autora especialmente Aristóteles que se opõe ao mentalismo da modernidade e analisa o ser humano como um vivente entre outros, voltado para o mundo e para sua comunidade, educando-se na medida em que descobre o mundo e os outros, adquirindo por ações e hábitos corretos um fazer e um saber que o situam em sua própria comunidade. Seria válido, portanto, apresentar dois filósofos contemporâneos como Tugendhat e Ricoeur, pois eles voltaram constantemente aos gregos para justificar suas posições para compreender o que é o humano.

\section{A posição de Ricoeur}

Ricoeur ao tentar pensar sobre o ser humano, nos fala de um Cogito ferido, cujo anticogito de Nietzsche representa o fim das críticas ao cogito que desembocam no paradoxo do mentiroso, ou seja, ao falar que minto, nego a mentira e falo a verdade, isto é, incorro em uma contradição performativa. Ricoeur citando Nietzsche em Vérité et Mensongeausens extramoral (1873), nos afirma que, desde as primeiras linhas a vida é colocada, aparentemente, em um sentido referencial e não figurado. Ricoeur reconhece que esse ato de Nietzsche significa um gesto de recusa à metafísica. O paradoxo inicial é aquele da ilusão de estar à serviço da conservação da vida, mas a natureza mesma se subtrai ao poder do homem em decifrar esta ilusão. Além disso, o que Nietzsche pretendia era também negar o neopositivismo, na medida em que este afirmava que o real é redutível a fatos e Nietzsche contrapunha "não há fatos, 
mas apenas interpretações dos fatos" ". Cabe aqui um argumento a favor de Ricoeur, na medida em que o homem já decifrou seu código genético e busca imitar o cérebro com a inteligência artificial, AI. Neste particular, podemos constatar com Ricoeur, que ainda falta muito a descobrir. Ricoeur mesmo discutiu esta questão com um neuro-cientista na obra em diálogo, intitulada O que nos faz pensar?"6

Ricoeur (1990) afirma que são tantos os prós e contra a uma filosofia do sujeito que ela atualmente não tem lugar na filosofia, entretanto o autor vai encontrar um lugar para o sujeito, enquanto si mesmo na própria linguagem. No seu primeiro estudo, a pessoa é a referência identificante, é ela a totalidade física e psíquica a qual podemos identificar. Ricoeur (1990) afirma que lógicos e epistemólogos reagrupam, sob o título comum de operadores de individualização, descrições definidas tais como o primeiro homem que pisou na lua, Sócrates etc... O que se passa é que nós somos particularmente interessados em individualizar os agentes do discurso, entretanto para que haja interlocução precisamos de pronomes pessoais e dêiticos. Ricoeur cita também Os Indivíduos de P. F. Strwason, comentando que esse autor desenvolve uma estratégia que especifica, cada vez mais, os particulares de base que permitem a identificação de alguém. Segundo essa estratégia, os corpos físicos e as pessoas podem ser identificados. Nesse sentido os corpos físicos e as pessoas que somos são conceitos primitivos cujo argumento não pode derivar de outra coisa. A pessoa, identificada como uma coisa, não é nada mais que uma referência identificante, portanto não se trata do poder de autodesignação, mas que todos quando realizam a identificação se refiram à mesma coisa, ou seja, a ipseidade. O que importa é que todos os interlocutores designem a mesma coisa. O primado da referência identificante, assim atribuído particularmente, é uma noção cardinal de reidentificação. O que eu nomeio como um corpo é uma coisa material. Ainda segundo Ricoeur (1990) que segue recorrendo a Strawson em Os Indivíduos, eu atribuo à mesma coisa dois tipos de predicados, os físicos e os psíquicos. Além disso, é preciso adquirir simultaneamente a ideia de reflexividade e a ideia de alteridade para passar de uma correlação fraca para uma correlação forte entre o "si mesmo" para o a "ti mesmo", no sentido do outro e do meu (p. 55-136).

Podemos constatar que Ricoeur para problematizar a questão do sujeito não se remonta mais aos gregos, pois estes não valorizavam o problema do sujeito, próprio da modernidade, mas tenta mostrar com suas análises da Filosofia da Linguagem que é possível colocar a questão por meio de uma pragmática linguística. Ricoeur justifica esse ponto de partida porque a pragmática não pretende realizar uma descrição empírica dos fatos da comunicação, mas sim analisar as condições de possibilidade que determinam o emprego efetivo da linguagem, nos casos em que a

5 As citações de Nietzsche são do próprio RICOEUR, Paul. Soi même comme un outre. Paris: Éditions du Seuil, 1990. Utilizou-se também a tradução espanhola, RICOEUR, Paul, Sí mismo como outro. Madrid: Siglo XXI Editores.

6 Trata-se de um diálogo com um neurocientista: CHANGEUX, Jean Pierre; RICOEUR, Paul. O que nos faz pensar? Lisboa: Ed. 70, 2001. 
referência, vinculada a certas expressões, não possa ser determinada sem o contexto de seu uso, ou seja, da situação de interlocução. Podemos constatar, portanto, que Ricoeur para iniciar a análise da questão do sujeito parte de um fato que se dá no mundo, ou seja, da interlocução entre sujeitos, desta forma ele não quer falar de um sujeito isolado, mas do si mesmo e do outro, o que no caso da educação seria o professor e o aluno. Essa observação de Ricoeur é crucial no espaço pedagógico, pois se trata de professor e alunos se identificarem mutuamente.

Ricoeur citando Austin e Searle mostra que a linguagem é performativa e é nesta dimensão do dizer como fazer que a linguagem se inscreve no plano da ação. Assim para Ricoeur (1990) a Filosofia da Linguagem desempenha duas tarefas, a função de referência identificante que indica a pessoa e a função do sujeito que fala para comunicar-se com um outro (segunda pessoa) ficando excluída a terceira pessoa, que no caso é uma não-pessoa. O que interessa a Ricoeur é, portanto examinar como se dá o reconhecimento do outro e a comunicação, tanto real, mas especialmente na narrativa?

Ricoeur (1990) além de abordar a tradição analítica, traz também para suas análises as abordagens fenomenológica e hermenêutica. Segundo o autor, as investigações analíticas não dão conta de um sujeito capaz de designar-se a si mesmo, significar o mundo e abrir-se para o outro. Nas análises fenomenológicas, são importantes as questões do corpo próprio, limite material e vital pelo qual habitamos o mundo e nos expomos para o outro, assim como o corpo do outro aparece a nós, em sua realidade, constituindo a base de toda a comunicação.

Ricoeur (1990) traz ainda anoção de caráter e de sua posição na problemática da identidade. O autor conceitua caráter como um conjunto de disposições duradouras por meio das quais reconhecemos uma pessoa, sendo que a questão do ipse e do idem não se distinguem uma da outra no caráter. Assim Ricoeur começa sua primeira concepção antropológica seguindo Aristóteles para o qual êthos (caráter) e ethos (costume) estão muito próximos. Do termo êthos para hexis (disposição adquirida) se constrói a base antropológica para uma ética, na medida em que as virtudes adquiridas são objeto da adoção de regras corretas segundo o homem prudente (prhónimos).

A primeira visão antropológica, Ricoeur acentuava a finitude e a vulnerabilidade do ser humano, por meio do fechamento da existência finita, do caráter como algo dado que faz com que eu seja eu na minha particularidade, mas também da abertura para a infinitude e busca da felicidade. Assim, nessa particularidade, aparece para uma Antropologia atenta uma espécie de falha na existência que torna possível a labilidade, uma espécie de fragilidade que pode conduzir a falhas e ao mal. Desta forma, é por esta desproporção e labilidade que o homem pode aceder

\footnotetext{
7 Aqui também se trata da força ilocucionária que é condição de possibilidade da atestação, ou seja, da identidade idem e da identidade ipse, enquanto reconhecimento de si mesmo.
} 
ao mal, mas também éessa desproporção que o caracteriza como ser humano. Neste ponto, Ricoeur concorda com Nussbaum (1986) que afirma o caráter de fragilidade do bem em sua prática ${ }^{8}$.

É preciso, entretanto, acentuar que Ricoeur, em sua visão antropológica, está centrado também na narrativa e no texto. Desta forma, em um esquema de análise da ação humana, Ricoeur vê a identidade do ser humano como a de um personagem que se narra, na medida em que essa mesma identidade é uma existência temporal. A identidade do personagem só se deixa compreender por um movimento dialético de concordância e discordância desenvolvido por meio da trama da ação. Segundo a linha da concordância o personagem adquire sua singularidade da unidade de sua vida, considerada como totalidade temporal própria que o distingue de qualquer outro. Na linhada discordância essa totalidade temporal está ameaçada pelo efeito da ruptura dos acontecimentos imprevisíveis que vão surgindo na evolução da vida e que são fruto de escolhas, às vezes acertadas, às vezes não. É importante acentuar que somente encarando sua própria vida como uma narrativa que o ser humano pode se abrir para uma perspectiva ética.

A outra consideração antropológica de Ricoeur é, portanto, mais positiva do que a do homem falível e limitado. Ricoeur em suas reflexões antropológicas fala de uma intencionalidade ética que se constitui em desejar uma vida boa com e para o outro em instituições justas. Neste ponto Ricoeur segue Aristóteles e destaca que a grande lição que ele nos legou foi de haver buscado na práxis o fundamento da pergunta pela vida boa. Neste ponto, a vida não se coloca apenas no plano biológico, mas a palavra vida adquire uma dimensão apreciativa e valorativa do ser humano enquanto tal, caracterizando o sentido ético e cultural, próprio dos gregos. Ao comentar a questão da deliberação Ricoeur, embora traga o pensamento de Aristóteles, não deixa de dirigir-lhe uma crítica, na medida em que Aristóteles afirma que só podemos deliberar sobre as coisas que dependem de nós, portanto deliberamos sobre os meios, ficando os fins do lado do desejo (boulesis). Alem disso, conforme Aristóteles não podemos deliberar até o infinito. Neste ponto Ricoeur faz sua crítica a Aristóteles questionando se, quando elegemos entre diversos cursos de ação, não estaríamos perguntando por um ideal de vida e, portanto por fins.

Ricoeur apresenta então a ideia aristotélica de amizade para demonstrar que o si mesmo só existe em referência a si mesmo e com o outro. Procurando evitar a gênese do ser com, a partir da posição de Husserl que o faz derivar da mesmidade ou a partir de Lévinas que o deriva da presença e do apelo do outro, Ricoeur afirma retirar de Aristóteles a ideia de que o reconhecimento do outro reside na reciprocidade e mutualidade, quando na verdadeira amizade o eu e o outro se reconhecem como portadores dos mesmos direitos e das mesmas qualidades. Neste ponto, Ricoeur introduz, novamente, uma crítica a Aristóteles, pois este faz derivar a amizade da simetria e mutualidade entre os indivíduos,

8 A citação de Nussbaum é do próprio Ricoeur. Ver NUSSBAUM, Martha C. The fragility of Goodness, Luck and Ethics in Greek Tragedy and philosophy. Cambridge: Cambridge University Press, 1986.

Educação Por Escrito, Porto Alegre, v. 7, n. 1, p. 16-33, jan.-jun. 2016 
enquanto Ricoeur em sua ética baseia o mutuo reconhecimento na solicitude, ou seja, não há necessidade de simetria para o ser com, mas sim do ponto de partida de que todos, mesmo os que não têm iguais possibilidades de ação, como as crianças, os idosos e os enfermos são capazes de se abrir para o outro e nos ensinar algo. Essa colocação de Ricoeur traz uma contribuição importante para a relação pedagógica que é assimétrica, mas tal assimetria que ocorre no movimento da intencionalidade pedagógica se dá na visão do bem do aluno. A ética da solicitude é, portanto, a originalidade do pensamento de Ricoeur e abre as portas para o reconhecimento das diferenças. Desta forma, a segunda visão antropológica de Ricoeur, que se integra à antropologia do homem finito e falível, é a antropologia do homem capaz. O homem capaz é aquele que pode reconhecer o outro, que pode se recordar, que pode imputar a si mesmo seus próprios atos e principalmente alguém que pode se narrar, fazer história e perdoar (2000, p. 5-66 e p. 595-656).

Ricoeur como homem de seu tempo não deixou de questionar em sua antropologia o homem em seu sonho tecnológico. Segundo esse sonho, o cérebro é considerado um equivalente substituível da pessoa. O cérebro, na alta tecnologia, ou seja, nas experiências de vivisecção, de transplante, de reduplicação, de teletransporte representa o ser humano enquanto manipulável (1990, p. 178-1799).

\section{A posição tecnológica}

Sloterdijk (2011) na atualidade sugere trocar a ideia de círculo hermenêutico pela de círculo antropotécnico. Do enunciado há informação dependem outros como: há sistemas, há memórias, há culturas, há inteligência artificial. Do enunciado há genes se revela o salto do princípio da informação sobre a esfera da natureza. As relações eu - mundo, indivíduo e sociedade perderam seu brilho. O que conta são memórias existentes, sistemas que se autoorganizam, ficando obsoleta adistinção entre natureza e cultura, tornando-se estas distinções apenas as diferenças regionais de estados de informação e seu processamento. Se estas constatações deste autor funcionam nas sociedades altamente evoluídas, mesmo que grande parte dos seres humanos ainda se encontre longe desta consciência dos fatos, a verdade é que a parte que está fora desse círculo é levada a consumir suas sobras e suas consequências.

A educação empirista e cognitivista da modernidade torna nossa escola obsoleta diante do mundo digital. As crianças e adolescentes, nativos digitais perdem o interesse pela escola, pois o ambiente virtual significa um jogo sem consequência. Um sistema escolar que ainda não aprendeu a imersão no virtual favorece esse tipo de semicultura e

\footnotetext{
9 Novamente Ricoeur refere-se à tecnologia em termos de experimentos de neurociência que manipulam o ser humano.Ver CHANGEUX,
} Jean Pierre L'homme neuronal. Paris: Fayard, 1983.

Educação Por Escrito, Porto Alegre, v. 7, n. 1, p. 16-33, jan.-jun. 2016 
meia-educação para usar uma expressão de Adorno (1995). Não é objetivo desse trabalho analisar ou criticar o mundo tecnológico, mas constatar que ele está no nosso horizonte. Apenas tentamos assinalar que uma nova antropologia como antropotécnica desafia as concepções de ser humano e educação, avançando com seus efeitos para ações que, nasua neutralidade ética, podem levar a consequências imprevisíveis ${ }^{10}$.

Lemos (2009) em seu comentário sobre as mídias afirma que movimentar é sempre deslocar, o que poderia parecer uma indiferenciação de lugares, entretanto o deslocamento, enquanto mobilidade física e informacional, não significa o desaparecimento da dimensão espacial em sua materialidade e suas dimensões sociais, políticas e econômicas. A mobilidade informacional, aliada á mobilidade física não apaga os lugares, mas os redimensiona. Essa mobilidade é um poderoso recurso desde que usado com prudência e significado pedagógico, o que nem sempre é o caso.

Santaella (2010) comenta as mudanças que ocorrem quando usamos o mouse e as telas sensíveis ao toque. A primeira condição do processo é um estado de alerta. Depende também de uma coordenação viso-motora aprimorada do infonauta a ponto de habilitar as reações motoras a lidar instantaneamente com mudanças visuais dinâmicas. Por outro lado, manipular a máquina exige automatismos sensório motores que implicam em movimentações perceptivas no ambiente, tanto quanto em passes ligeiros de inferências mentais. Além do mais, quando se passa para telas sensíveis ao toque, o tato ganha uma proeminência lúdica jamais alcançada, na medida em que os dedos tocam de forma direta o mesmo plano da imagem da tela. Santaella citando Merlau Ponty afirma que as vicissitudes da expansão perceptiva que o ciberespaço apresenta não são capazes de quebrar a unidade tempo-espacial e intersensorial do corpo, consequentemente qualquer ferramenta que nos conecta ao mundo virtual significa uma extensão do corpo próprio, existindo ambos no mundo.

Santaella (2011) aborda o estatuto do corpo humano quando o mesmo enquanto unidade psicofísica, imerge nos espaços informacionais e devido a forma de pensar a partir de dualismos acaba deixando a questão da corporeidade e a questão da identidade de certa forma ambíguos. A autora cita Tenhaaf que imputa ao virtual um poder metafísico, como um recurso de controle que se autossustenta para além da autoria, enquanto aparato simbólico fora do eu com a capacidade de ordenar a representação e construir o sujeito percebedor (apud SANTAELLA, 2011).

Há muitos autores que concordam com essa posição de que a informação começa a seguir seu próprio caminho extrapolando o humano. Por outro lado, Hayles se contrapõe à superioridade da informação no sentidoda

\footnotetext{
${ }^{10}$ Refiro-me a obra de Horkheimmer e Adorno A dialética do Iluminismo, na qual os autores se mostram totalmente desencantados com o progresso da ciência e da técnica, especialmente em seus resultados para a educação. Ver ADORNO, Theodor; HORKHEIMER, Max. Dialética do Esclarecimento. Rio de Janeiro: Jorge Zahar Editor, 1985.
} 
imaterialidadee argumenta que acreditar que as mídias computacionais são tecnologias desencarnadas é uma questão de construção histórica. Segundo esse autor não se pode ignorar a materialidade das interfaces que criam e os efeitos dessas interfaces nos usuários (apud SANTAELLA, 2011). Outro autor citado por Santaella questiona se podemos estar totalmente presentes, quando vivemos por meio de um corpo que está em nosso lugar e se dá conta que não tem a fragilidade e vulnerabilidade de nossa identidade primária, então quanto mais tomamos a máquina por nós mesmos, mais nos damos conta do caráter de prótese da própria máquina (HAYLES apud SANTAELLA, 2011).

Santaella apresenta então uma terceira posição que menciona corpos carnais e corpos alternativos, pois a autora julga ser as oposições entre o virtual e o real e o virtual ao físico um equívoco epistemológico. A autora ainda acrescenta que quando julgamos o que percebemos há duas representações simultâneas e distintas a do corpo carnal e as dos corpos alternativos. A autora cita Merlau Ponty, apontando para a ideia que somos no mundo, que o habitamos de forma espaço-temporal, desta maneira essa forma de unidade intersensorial não se encontra fortuitamente associada, mas se coloca como condição dessa mesma associação. Isso ocorre quando o corpo está envolvido em suas tarefas, enquanto existe em direção a elas e se recolhe em si para atingir uma meta, estando a percepção envolvendo todo o corpo em integração indissolúvel com a mente, enquanto se debruça sobre as redes de signos, sobre os instrumentos e arquiteturas líquidas do ciberespaço. A autora conclui afirmando a existência de um continuum perceptivo que inclui a percepção do próprio corpo, do seu entorno e a estimulação sinestésica que o ciberespaço coloca diante do percipiente e ao qual ele reage como agente performativo, interagindo perceptiva e mentalmente aos estímulos sensório voláteis que se apresentam. Toda a argumentação de Santella parece se dirigir para o fato de não podemos negar que estamos envolvidos pelas redes midiáticas e que elas transformam nossa identidade na medida em que descobrimos suas possibilidades.

Castells (2007) afirma que nosso mundo e nossa vida têm sido moldados pelo conflito entre globalização e identidade. Nossa sociedade adquire uma nova forma por meio das tecnologias de informação e globalização das atividades econômicas, estrategicamente organizadas em rede, pela flexibilização e instabilidade do seu emprego. Diante da realidade que se apresenta com a revolução tecnológica, com a transformação do capitalismo que cria riqueza e ao mesmo tempo induz a exclusão, surgem como reação poderosas identidades sociais de diferentes significados culturais que constroem suas identidades em função da forma como percebem a agressão do capitalismo tecno-econômico.

Castells (2007) entende por identidade o processo de construção do significado com base num atributo cultural ou um conjunto desses atributos inter-relacionados para os quais prevalecem outras formas de significado, as identidades constituem fontes de significado para os próprios atores por elas construídas por meio de um processo de individualização. 
Castells (2007) propõe três formas e origens de construção de identidades:

- identidade legitimadora: introduzida pelas instituições dominantes da sociedade no propósito de expandir e racionalizar sua dominação sobre os atores sociais.

- identidade de resistência: criadas por atores estigmatizados e excluídos pela lógica da dominação que se apresentam como resistência e sobrevivência, com base em princípios diferentes dos que permeiam as instituições da sociedade.

- identidade de projeto: quando os atores sociais servindo-se de qualquer tipo de material cultural ao seu alcance, constroem uma nova identidade capaz de redefinir a sua posição na sociedade, buscando a transformação de toda a estrutura social (CASTELLS, 2007).

Essas formações de identidade social tem sua possibilidade de construção por meio das mídias sociais, especialmente da internet. Tais formações de identidade midiática implicam tanto nos algoritmos do hardware e software que são linguagens técnicas, como na linguagem ordinária, própria das interações com a máquina. Essa interação exige o domínio de uma linguagem operacional e uma linguagem interpretativa para que a interação tenha significado. É em função dessa exigência que aparece o perigo de uma mobilidade sem sentido, que aparece no copiar e colar, praticado de forma usual pelos estudantes, ficando de lado uma atividade interpretativa e compreensiva dos conteúdos pesquisados. Parece faltar tanto para os professores como para os alunos uma problematização maior dos conteúdos com os quais eles lidam, ou seja, há falta de uma aprendizagem significativa.

Diante da visão, de certa forma determinística, de Sloterdijk e otimista de Santaella e Castells, Hermann (2014) afirma que já que não estamos mais em condições de identificar quem somos, já que muitas vozes nos cercam, vale, portanto, tentar uma fenomenologia do outro, não como outreidade, mas como o outro que se apresenta a mim. A autora fazendo uma cuidadosa imersão em Husserl e Waldenfels apresenta a experiência do outro, como algo que não começa com nossa intenção, nem provém de um entendimento comum, mas como algo que nos acontece. Em seu estudo de Waldenfels a autora se refere a dois tipos de respostas que tem sido dada. Um dos caminhos é o que afirma o universal formal que parte da identidade e sonega a pluralidade. O outro caminho é o que conduz ao individualismo centrado em si mesmo. Hermann (2014) no mesmo artigo é muito feliz no exemplo pedagógico citado para esclarecer tal situação. Segundo a autora:

O universal formal, presente nas idealidades pedagógicas, define padrões de comportamentos, características e normas de ação para alunos que deixam escapar aquilo que não se enquadra nessa determinação. Frequentemente sofre preconceitos quem não aprende no mesmo ritmo, não demonstra certas habilidades específicas como a habilidade lógico-matemática, ou apresenta dificuldades na linguagem oral, porque o 
ideal, definido abstratamente, exige do aluno as características desde já pressupostas não só pelo professor, como também pela organização curricular e didático-pedagógica. O individualismo exacerbado, por sua vez, cria dificuldades de interação, pois o que extrapola o restrito âmbito do eu obstaculiza o reconhecimento do outro; mais do que isso, não permite abertura à experiência [...] (HERMANN, 2014, p. 485).

Continuando as análises de Waldenfelds, a autora propõe a experiência do outro como estranheza radical, o que ela aponta como impossível, visto que diferenciamos o outro sempre a partir de um ponto de referência (inclusão/ exclusão, dentro/fora). Há também a possibilidade de encontrarmos o outro a partir de nosso próprio estranhamento. Na medida em que me percebo como um estranho para mim mesmo me dou conta do que pode ser o outro, o estranho. Segundo Hermann (2014), esta posição se encontra fora da clássica posição ocidental da possibilidade do diálogo. Nesse sentido, há o outro e há o si mesmo. Waldenfelds assim como Ricoeur propõe que reconhecer o outro exige um movimento original de mão dupla em que o outro se apresenta como singularidade diante de mim, caracterizando um acontecimento inevitável e assimétrico. Ricoeur dá a resposta da solicitude. Somente uma atitude de abertura total ao outro e o reconhecimento de minha própria insignificância e fragilidade é capaz de manter frente a frente duas pessoas que reivindicam igual respeito.

Segundo Miranda (2014), trabalhando Lévinas, autor muito caro a Ricoeur, essa via de mão dupla ocorre em um jogo de estranhamento e familiaridade. Segundo o autor o outro me desafia colocando-me face à face com sua estranheza, forçando uma resposta que me torna responsável pelo outro. $\mathrm{O}$ autor destaca ainda a ética como filosofia primeira, na medida em que é a alteridade do Outro que constitui a subjetividade ética. É uma subjetividade que se mostra como acolhimento, na forma da hospitalidade ao estrangeiro que vem ao nosso encontro e reivindica nossa responsabilidade e nossa inteira aceitação. Assim a inscrição da responsabilidade, na subjetividade é algo que acontece para o outro. No ato educativo esse outro é nosso aluno que precisamos reconhecer, em sua dignidade e inteireza. Como na proposta de solicitude, colocada por Ricoeur a experiência educativa, como posição ética se dá como proximidade, acolhimento e aceitação do outro, assim como minha aceitação de mim mesmo. Isso, entretanto exige do professor uma formação que o torne plenamente consciente da importância de preparar-se para esta aceitação, numa dimensão infinitamente mais profunda que uma antropotécnica.

\section{Considerações finais}

Partimos do relatório da CONAE 2014 que nos fala de um novo projeto educacional que contemple uma Antropologia e uma ética que fale na primeira e segunda pessoa. O relatório parte também de uma educação renovada 
que possa trabalhar na forma de uma transdisciplinaridade por meio da qual os professores possam planejar em conjunto projetos que interessem e captem a motivação e participação de crianças e adolescentes. O relatório prepara o Plano Nacional de Educação (2014-2024) e é a base do documento Pátria Educadora.

Por outro lado, salienta a importância da avaliação, tanto dos docentes, como dos discentes, não para rotulá-los, mas para refletir constantemente sobre acertose erros, já que somos seres vulneráveis e passíveis de falhas.

O documento da CONAE 2014 aborda também a questão das tecnologias da comunicação. Precisamos de professores e alunos com projetos imersivos nas redes que possam construir identidades de projeto que resultem em aprendizagens significativas e cidadania consciente.

O trabalho desenvolvido pelos professores deve levar em conta os saberes de sua experiência, mas não pode permanecer na mera empiria. Os professores não devem temer o uso das tecnologias, considerando-as como ameaças ao seu saber. Devem buscar apoio em técnicos de informática com sensibilidade pedagógica que os auxiliem a resolver problemas técnicos e refletir sobre teorias pedagógicas, sem porém descuidar de uma reflexão mais aprofundada sobre uma antropologia e uma ética. Por outro lado, as escolas precisam de redes que funcionem, computadores e outros recursos tecnológicos no espaço de ensino e não nos laboratórios.

A sociedade da informação requer alunos e professores aprendendo juntos, imersos nas redes de comunicação. A assimetria inicial entre professor e aluno deve ser vencida por meio do reconhecimento do outro que é o aluno e pela solicitude do professor sensível as diferenças e disposto a encorajar, sobretudo aqueles que mais necessitam de ajuda.

A presença e o uso das tecnologias não devem ser fatores de reducionismo, mas sim ocasião para que se alarguem os horizontes culturais e o respeito por todas as culturas. Essa atitude, constantemente cultivada, como já foi dito, poderá ajudar na formação de identidades de projeto que possam exercer uma cidadania real que transforme as condições de nosso país, tão oprimido pelas elites dirigentes, insensíveisàs necessidades da maioria. Desta forma, a educação, cultivando e reconhecendo as necessidades do outro e desenvolvendo a base de uma ética da solicitude, assim como o uso significativo das tecnologias poderá entrever novos rumos tanto para o trabalho do professor, como para o desenvolvimento do aluno e construção de um sistema educacional mais justo. Um sistema educacional mais justo significa como base o acesso de todos a uma escola básica de qualidade e oportunidades de desenvolvimento e continuidade de educação para todos, sobretudo melhores condições de trabalho para os professores, formação continuada, plano de carreira e salários justos, pois sem uma vida digna os professores não terão a autoestima necessária para exercer sua complexa profissão.

O uso das redes de informação poderá auxiliar a construir uma cidadania ativa participante na sociedade e quepossa inserir-se no mercado de trabalho, controlar as ações de seus representantes políticos e colaborar para um 
desenvolvimento sustentável na medida em que interessar-se por acontecimentos sociais, ambientais, políticos e econômicos.

O reconhecimento do outro, enquanto destino original, e o cultivo da solicitude como reciprocidade e a relação com os outros em suas diferenças, deverão ser os pilares de um sistema escolar que não reaja negativamente à presença da tecnologia, mas que saiba fazer uso da mesma de forma não reducionista, não evitando as questões humanas, políticas, multiculturais e, sobretudo éticas, sabendo assumir um compromisso de exigências recíprocas.

Com essas conclusões julgamos ter levantado alguns pontos e reflexões filosóficas centrais do documento da CONAE 2014 para que suas indicações circulem mais, na medida em que for alvo de mais discussões e aprofundamento. Pois pensando mais claramente poderemos agir de forma mais acertada e promover uma sociedade mais justa. Essas considerações seriam a base do que se poderia caracterizar como próprias de uma Pátria Educadora que ultrapasse uma figura retórica e parta para a construção de sentidos mais justos. O documento sobre a pátria educadora, recentemente lançado, não precisa necessariamente ser interpretado como uma oposição a CONAE 2014 e ao PNE. Neste momento de urgências precisamos integrar esforços e buscar consensos, mesmo que os pontos de concordância sejam difíceis de entrever.

Fechando com uma frase lapidar de Ricoeur uma educação cultivada pela ética poderia se resumir em saber conviver consigo mesmo e com o outro em instituições justas.

\section{Referências}

CASTELLS, Manuel A Era da Informação: Economia, Sociedade e Cultura - o poder da identidade. Lisboa: Fundação Calouste Gulbenkian, 2007. 2 v. 627 p.

CONAE - Conferencia Nacional de Educação. Documento Referência. Ministério da Educação (MEC), 2014. Disponível em: <http:// conae2014.mec.gov.br/ images/pdf/docreferenciaconae2014.pdf>. Acesso em: mar. 2015.

DARWIN, Charles. A origem das espécies. São Paulo: Itatiaia, 1985.

DO VALLE, Lilian Para além do sujeito isolado modelos antropológicos para pensar a educação. Revista Brasileira de Educação, Rio de Janeiro: ANPED, v. 19, n. 57, p. 495-512, abr.-jun. 2014.

GOULD, Stephen Jay. Dinossauro no palheiro: reflexões sobre a história natural. São Paulo: Companhia das Letras, 2005.

HERMANN, Nadja. A questão do outro e o diálogo. Revista Brasileira de Educação, Rio de Janeiro: ANPED, v. 19, n. 57, p. 477-493, abr.-jun. 2014.

LEMOS, Andre; JOSGRILBERG, Fabio (Org.). Comunicação e mobilidade: aspectos socioculturais das tecnologias móveis no Brasil. Salvador: EDUFBA, 2009.

Educação Por Escrito, Porto Alegre, v. 7, n. 1, p. 16-33, jan.-jun. 2016 
MIRANDA, José Valdinei Albuquerque de Lévinas e a reconstrução da subjetividade ética. Revista Brasileira de Educação, Rio de Janeiro: ANPED, v. 19, n. 57, p. 461-475, abr.-jun. 2014.

NUSSBAUM, Martha C. The fragility of Goodness, Luck and Ethics in Greek Tragedy and philosophy. Cambridge: Cambridge University Press, 1986.

TUGENDHAT, Ernest. Antropologia como Filosofia Primeira. In: OLIVEIRA, Nythamar de; SOUZA, Draiton Gonzaga de (Org.). Hermenêutica e filosofia primeira. Ijuí (RS): Editora UNIJUÍ, 2006. p. 78-94.

RICOEUR, Paul. Temps et récit. Paris: Éditions du Seuil, 1983. Tome I. . Soi même comme um autre. Paris: Éditions du Seuil, 1990.

. La mémoire, l'histoire, l'oubli. Paris: Éditions du Seuil, 2000.

SANTAELLA, Lucia. A ecología pluralista da comunicação. São Paulo: Paulus, 2010.

SANTAELLA, Lucia. Comunicação ubíqua. São Paulo: Paulus, 2013.

SLOTERDIJK, Peter. Sin salvacion tras las huellas de Heidegger. Madrid: Ediciones Akal, 2011.

Recebido em: junho 2015

Aceito em: dezembro 2015

Endereço para correspondência:

Rosa Maria Filippozzi Martini

Av. Vítor Barreto, 2288 - Centro

92010-000 Canoas, RS, Brasil

<rosa.martini@unilasalle.edu.br> 